\section{Inhibition of astrocyte activation is involved in the prevention of postoperative latent pain sensitization by ketamine and gabapentin in mice}

Sir,

The pharmacologic management of postoperative pain has currently a double purpose: On one hand to reduce the intensity of the acute pain after surgery, and, on the other hand, to prevent the development of chronic postsurgical pain. Previous studies have shown that an inhibition of the glial activation is involved in the prevention of postoperative hyperalgesia $(\mathrm{POH})$ by ketamine (KET) and gabapentin (GBP). ${ }^{[1,2]}$ However, only a few data exist on the involvement of the glial activation in the prevention of the postoperative latent pain sensitization (PS) mediated by KET or GBP.

Because of this, the antihyperalgesic effects of KET and GBP were evaluated in a plantar incision pain model (previously validated in our laboratory in mice, ${ }^{[3]}$ which mimics the characteristics of the postoperative pain in humans. The work was in agreement with both the European Directive 2010/63/EU and the Ethical Guidelines-International Association for the Study of Pain. The protocol was approved by the institutional review board (CEEA-PRBB, Spain). We assessed $\mathrm{POH}$ and PS, the later substantiated by a naloxone $(1 \mathrm{mg} / \mathrm{kg})$ challenge, using Von Frey filaments (10-12 animals/group). Activation of microglia and astrocytes was evaluated by immunochemistry (4-5 animals/group and time point) of the L4-L6 segments of the spinal cord. Systemic KET $(50 \mathrm{mg} / \mathrm{kg})$ and GBP $(100 \mathrm{mg} / \mathrm{kg})$ were administered intraoperatively just before surgical closure to mimic the postoperative analgesia administration in clinical practice. Drug doses were selected among those effective in previous studies on postoperative pain in mice. All animals received the same inhaled concentration of sevoflurane $(3.0-3.5 \%$, v/v) during $30 \mathrm{~min}$.
Surgery (incision plus saline, INC + SS group) induced a significant $\mathrm{POH}$ in mice at $4 \mathrm{~h}$ and 1 day. On days 20-21, naloxone, but not saline, administration induced hyperalgesia of a similar magnitude to day 1 [Figure 1]. KET (INC + KET) and GBP (INC + GBP) partially prevented $\mathrm{POH}$ at $4 \mathrm{~h}$ and 1 day $(P<0.001)$, and PS at 21 day after naloxone $(P<0.001)$ [Figure 1]. No hyperalgesia was observed in sham-operated animals at any time point (control group, data not shown). Glial immunoreactivity was assessed at day 1 , concurring with the period of maximal hyperalgesia, and also on day 21 after saline or naloxone administration. On day 1 , the increase in microglia immunoreactivity was prevented by KET and GBP $(P<0.001)$; neither saline nor naloxone administration on day 21 induced microglia re-activation [Figure 2]. Immunoreactive astrocyte activation on day 1 promoted by surgery was partially prevented by KET and GBP $(P<0.001)$. The administration of naloxone (but not saline) on day 21, induced astrocyte re-activation, which was partially prevented by both KET and $\operatorname{GBP}(P<0.001)$ [Figure 2] scale bars: panels $\mathrm{A}$ and B, $50 \mu \mathrm{m}$.

Our findings indicate that the antihyperalgesic effects of KET and GBP, two of the most important adjuvants currently employed in clinical practice to prevent chronic pain after surgery, could be partially mediated by an inhibition of microglia and astrocyte activation. It is known that N-methyl-D-aspartate -nitric oxide (NMDA-NO) pathways are involved in the development of hypersensitivity, and NO promotes glial fibrillary acidic protein expression in

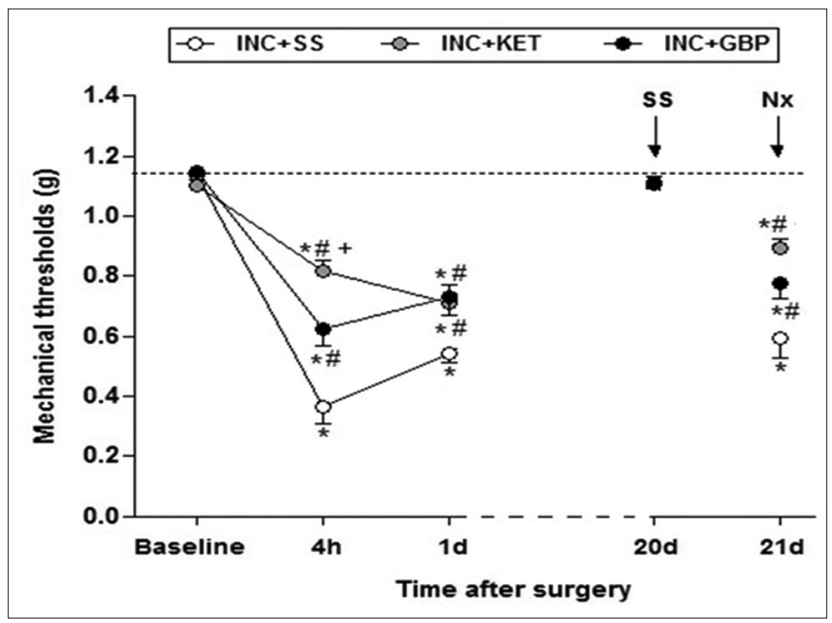

Figure 1: Effects of ketamine $(50 \mathrm{mg} / \mathrm{kg})$ and gabapentin $(100 \mathrm{mg} / \mathrm{kg})$ in a murine model of incisional pain. Data expressed as mean \pm standard error mean. ${ }^{*} P<0.001$ versus baseline; ${ }^{*} P<0.001$ versus INC + SS 


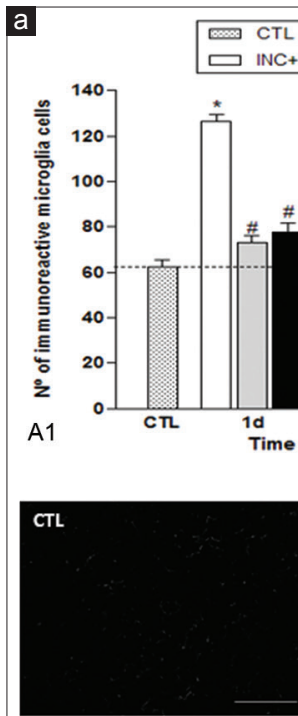

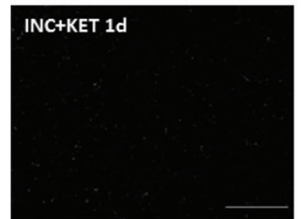

A2 b
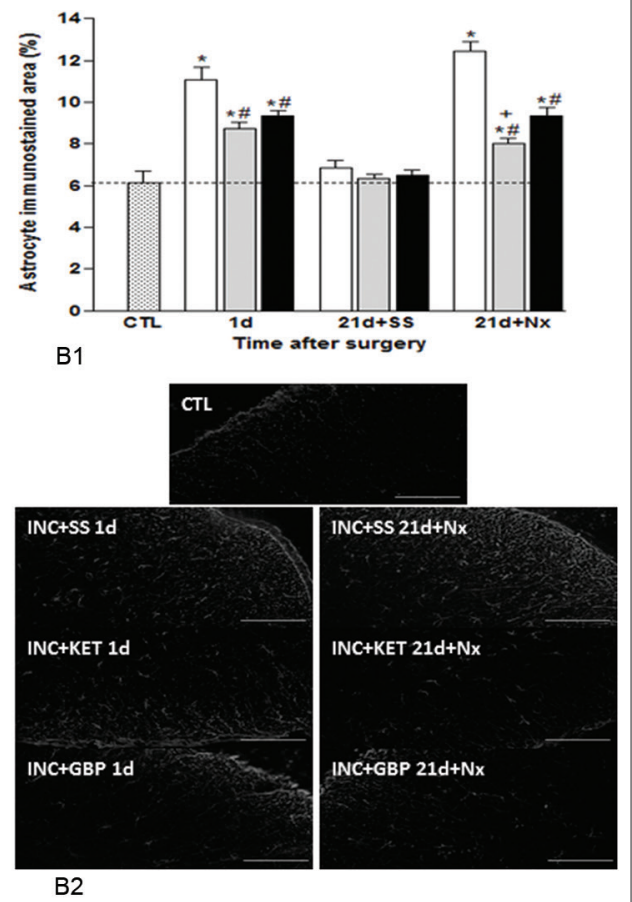

Figure 2: Effects of ketamine $(50 \mathrm{mg} / \mathrm{kg}$ ) and gabapentin $(100 \mathrm{mg} / \mathrm{kg})$ on: (a) Microglia immunoreactivity. A1: Histograms (mean \pm standard error mean): Number of ionized calcium binding adapter molecule 1 positive cells. A2: Representative photomicrographs of Iba-1 positive cells expression by immunofluorescence in spinal cord at day 1. (b) Astrocyte immunoreactivity. B1: Histograms (mean \pm standard error mean)\% of glial fibrillary acidic protein stained area. B2: Representative photomicrographs of glial fibrillary acidic protein expression by immunofluorescence in spinal cord, at 1 and 21 days after surgery. ${ }^{*} P<0.001$ versus baseline; ${ }^{\#} P<0.001$ versus INC + SS

astrocytes. ${ }^{[4]}$ Thus, the blockade of NMDA by KET could suppress NO liberation by NMDA neuronal receptors through the reduction of astrocyte immunoreactivity. The decrease of spinal glial activation by GBP could be due to an indirect modulation of the neuronal voltage-gated calcium channels $\alpha 2 / \delta-1$ subunits, ${ }^{[5]}$ concurrent with $\mathrm{Ca}^{2+}$-dependent glutamate release from astrocytes. ${ }^{[6]}$

To the best of our knowledge, this is the first time that a delayed astrocytic activation, concomitant with a PS partial inhibition, has been shown to be partially prevented by KET and GBP in a model of post incisional pain. Further studies are warranted.

\section{Acknowledgment}

The authors thank Dr. Covas from NUPROAS Handesbolag for her excellent editing of the manuscript.

\section{Financial support and sponsorship}

The word was supported by grants from Fondo de Investigación Sanitaria, Instituto de Salud Carlos III, Madrid, Spain (PS09/01270), and the Endowed Chain in Pain Management, Universitat Autònoma de Barcelona-Parc de Salut MarMenarini (MMP).

\section{Conflicts of interest}

There are no conflicts of interest.

\section{Elizabeth Romero-Alejo, Margarita M. Puig, Asunción Romero}

Department of Anesthesiology, Pain Research Unit, Universitat Autònoma de Barcelona, Barcelona, Spain

Address for correspondence: Asunción Romero, Department of Cellular Biology, Physiology and Immunology, Faculty of Veterinary Medicine, Universitat Autònoma de Barcelona, Barcelona, Spain. E-mail: mariaasuncion.romero@uab.cat

Received: 27-09-2015

Revised: 04-11-2015

Accepted: 01-02-2016

\section{REFERENCES}

1. Mei XP, Zhang H, Wang W, Wei YY, Zhai MZ, Wang W, et al. Inhibition of spinal astrocytic c-Jun N-terminal kinase (JNK) activation correlates with the analgesic effects of ketamine in neuropathic pain. J Neuroinflammation 2011;8:6.

2. Hayashi Y, Kawaji K, Sun L, Zhang X, Koyano K, Yokoyama T, et al. Microglial $\mathrm{Ca}^{2}+$-activated $\mathrm{K}^{+}$channels are possible molecular targets for the analgesic effects of S-ketamine on neuropathic pain. J Neurosci 2011;31:17370-82.

3. Célérier E, González JR, Maldonado R, Cabañero D, Puig MM Opioid-induced hyperalgesia in a murine model of postoperative pain: Role of nitric oxide generated from the inducible nitric oxide synthase. Anesthesiology 2006;104:546-55

4. Bortolanza M, Cavalcanti-Kiwiatkoski R, Padovan-Neto FE, da-Silva CA, Mitkovski M, Raisman-Vozari R, et al. Glial activation is 


\section{Research Letter}

associated with 1-DOPA induced dyskinesia and blocked by a nitric oxide synthase inhibitor in a rat model of Parkinson's disease. Neurobiol Dis 2015;73:377-87.

5. Yang JL, Xu B, Li SS, Zhang WS, Xu H, Deng XM, et al. Gabapentin reduces CX3CL1 signaling and blocks spinal microglial activation in monoarthritic rats. Mol Brain 2012;5:18.

6. Yoshizumi M, Eisenach JC, Hayashida K. Riluzole and gabapentinoids activate glutamate transporters to facilitate glutamate-induced glutamate release from cultured astrocytes. Eur J Pharmacol 2012;677:87-92.

This is an open access article distributed under the terms of the Creative Commons Attribution-NonCommercial-ShareAlike 3.0 License, which allows others to remix, tweak, and build upon the work non-commercially, as long as the author is credited and the new creations are licensed under the identical terms.

\begin{tabular}{|l|l|}
\hline \multicolumn{2}{|c|}{ Access this article online } \\
\hline Quick Response Code: & Website: \\
\hline & www.jpharmacol.com \\
\cline { 1 - 2 } & \\
\hline & DOI: \\
\cline { 2 - 3 } & $10.4103 / 0976-500 \times .179357$ \\
\hline
\end{tabular}

How to cite this article: Romero-Alejo E, Puig MM, Romero A. Inhibition of astrocyte activation is involved in the prevention of postoperative latent pain sensitization by ketamine and gabapentin in mice. J Pharmacol Pharmacother 2016;7:22-4. 